\title{
BREAKING THE CYCLE OF CHILD ABUSE IN MALAYSIA: LINKING MANDATORY REPORTING, SERVICE DELIVERY MONITORING AND REVIEW CAPACITY MECHANISMS
}

\author{
Bala Raju Nikku(Ph.D) \\ Visiting Sr.Lecturer \\ Social Work Section \\ School of Social Science \\ Universiti Sains Malaysia \\ \& Founding Director, Nepal School of Social Work \\ (brnikku@usm.my)
}

\author{
Azlinda Azman (Ph.D) \\ Associate Professor and Head of Social Work Section \\ School of Social Science \\ Universiti Sains Malaysia \\ (azlindaa@usm.my)
}

\begin{abstract}
The objective of this paper is to review the current thinking and action concerning breaking the cycle of child abuse in Malaysian society. The purpose is to illustrate some of the key issues, questions, and concerns for professional social work in the field of child abuse. The paper focuses on what social workers need to know and what do they know about child protection, and how to improve child abuse reporting, monitoring and review capacities in order to break the mould of child abuse and to craft a robust child protection system in Malaysia.
\end{abstract}

Keywords: Child Abuse, Malaysia, Social Work, Policy, Legislation, Mandatory Reporting

\section{INTRODUCTION}

Child abuse and neglect is a new term for an old problem, because child abuse has been in existence for centuries. Historically, every society has had covert and overt ways of handling the affect-laden problem of child sexual abuse. Children are arguably the most criminally victimized people in the world. They suffer high rates 
of all the same crimes that adults do, plus a load of offenses specific to their status as children, such as child maltreatment. They are beaten by family members, bullied and attacked by schoolmates and peers, abused and raped by dating partners, and targeted by sex offenders in both physical and virtual realms.

The World Report on Violence and Health (2002) and the United Nations Secretary General's Study on Violence against Children (2006) stated that the child maltreatment - the physical, sexual and emotional abuse, exploitation and neglect of children - has been widely prevalent in all societies. According to recent global data, more than one in four children worldwide reported having experienced severe and frequent physical abuse, while child sexual abuse was experienced by nearly one in five females and one in eleven males (UNICEF, 2012).

Approximately 1,800 children die annually in the United States as a result of abuse and neglect, and approximately $80 \%$ of these children are under the age of 4 years (U.S. Department of Health and Human Services, 2011). WHO (2002) estimates that approximately 31000 children $<15$ years of age died due to homicide worldwide. Catani et al., (2008) reported that the yearly prevalence of child abuse in some developed countries, where the prevalence of severe physical abuse varied from 4 to 16 percent. The Malaysian society has displayed a deepening concern over steady increase (since 1990s) in reported cases of child abuse in the country.

\section{FACETS OF CHILD ABUSE}

All forms of child abuse have become a crucial issue of legal and policy concern today because it not only affects the child's present but also his/her future negatively. Child sexual abuse (CSA) clearly has immediate identifiable effects, consistent symptom patterns, and adverse long-term effects on both boys and girls (Powell, 1987).

Sexually abused children are typically inclined not to disclose their experiences due to feeling of guilt and shame, bonds of dependence upon perpetrators and their inability to understand the sexual meaning of the abuse (Karlsson \& Karkara, 2003). Evidence shows that most of the abuse takes place 
either in homes, families, schools, alternative child care institutions, hospitals and juvenile care homes, etc.

The Asian Centre for Human Rights or ACHR (2013) report stated that, between 2001 and 2011, India recorded at least 48,338 cases of abuse of children, an increase of 336 percent from 2,113 to 7,112 incidents a year. Most of the abuse/violence takes place against girls in schools and orphanages run by the state. The abusers are principals, teachers, staff members, or older guests. In governmentrun juvenile justice homes, the perpetrators were staff such as caretakers, security guards, cooks and other lower class employees, and senior inmates. In private/NGOrun homes, the offenders included managers/directors /owners/founders and their relatives and friends; caretakers, wardens, cooks, drivers, security guards, gatekeepers, senior inmates and outsiders including security forces. Four primary factors are complicit in this trend: lack of inspections, hundreds of unregistered children, the presence of "phantom" supervisory authorities, and the lack of separate facilities for males and females. The lasting effects of CSA cannot fully understand without understanding the role of social institutions in either endorsement or prevention of child sexual abuse in a particular country.

The long-term effects of CSA are multifaceted because of the consequences not only for the individual victim, abuser and family but also for society as a whole. Hence, Child Sexual Abuse (CSA) is a social, cultural, political and public health concern locally and globally (United Nations International Children's Emergency Fund [UNICEF], 2010; World Health Organization [WHO], 2006). Increasing number of clinical studies relate adult victims with eating disorders, borderline personalities, sexual dysfunction, and depression with history of sexual molestation during childhood. More recently, a significant number of adults who are diagnosed with multiple-personality disorder have been found to have histories of child sexual abuse (Kluft, 1985).

\section{CHILD ABUSE IN MALAYSIA}

Children comprise of one third of almost 30 million population of Malaysia. More than 70 percent of total families in Malaysia are now nuclear. Average of seven 
children in Malaysia was reported to be victims of child abuse each day in 2008. Out of 2,780 children reported abused in 2008, child neglect is the main form of abuse followed by physical and sexual abuse.

The breakdown of the three key forms of abuse is as follows. First, 952 child victims experienced neglect, meaning a caretaker failed to provide for the child's primary needs. Second, 863 child victims were physically abused, and 733 child victims were sexually abused, and 72 percent were incest. Third, 58 were abandoned babies (UNICEF, 2010).

Considering the stigma and attitudes of Malaysian public, most cases of child abuse goes unreported. Hence, the statistical overview presented above could be just the "tip of the iceberg". Statistic of the Malaysian Royal Police showed that child abuse, molestation and rape are on the increase, from 2236 cases in 2005 to 5744 cases in 2008. The numbers were alarming, since international experience suggests that reported cases are likely to represent only 10 percent of total cases perpetrated (Muda \& Alwi, 2012).

In the context of Malaysia various scholars touched upon different aspects of CSA which are useful in understanding the scale and extent of the issue. Munir (1993) on Child Protection; Yusoff et al., (2008) on international trends in child abuse prevention; Muda Fatimah and Alwi Ahmed Zaki (2012) on Children Act 2001 and child abuse; Noremy et al., (2012) on child abuse and external factors; Hasniza and Talaat (2012) on verbal child abuse and Malaysian Law and Choo and her team (2013) on reporting and teacher attitudes in Malaysia.

In Malaysia, majority of those who abuse children sexually are fathers, stepfathers or another relative. Sexual abuse has seen an alarming increase recently. About 49 percent of rape cases reported in 1985 involved children below 15 years. In this federal capital alone, the number jumped from 11 in 1987 to 37 in 1989. Hospital and police authorities believe actual figures could be higher. The All-Women's Action Society (AWAS) claims there are 10 unreported cases for every case reported. In most cases (67.8 percent), the perpetrators were natural fathers, stepfathers or siblings. It is the main reason for unreported cases, states a report of the Suspected Child Abuse and Neglect (SCAN). Detection occurs when the child 
complains of pain, and a medical examination is carried out (Women's International Network News, 1990).

Failure to provide care and supervision by primary caregivers has become the most frequent cause of death among children. Statistics from sexual crimes, domestic violence and child abuse investigation division of Malaysia indicate that children aged between one and seven, made up the highest number of abuse cases. To make the matter worst for children, the child protection system is also failing in breaking the cycle of abuse due to systemic issues, lethargy and burn out of social workers and budget cuts (Terling-Watt, 2000).

\section{Policy and legal measures}

The National Child Protection Policy (CPP) of Malaysia that has been implemented since July 2009 is a good standard of practice to look up for all who is concerned with the safety of children. The CPP outlines child protection principles that are consistent with the Convention on the Rights of the Child (CRC) and the Child Act 2001 (Act 611) of Malaysia. It focuses on advocacy, prevention, support services and research and development aspects for the protection of children.

Child abuse is an offence in Malaysia, punishable under the Child Act (2001) and the Penal Code (revised 1997). Offenders may be liable to a maximum fine of RM 50,000 or up to 20 years imprisonment, or both depending on the offence. Offenders may also be punished with whipping in addition to the fine and/or imprisonment.

Despite these legal provisions, an average of seven children is abused every day in Malaysia. Significant strides made by the Government in improving child protection measures in recent years fail to curb the problem. UNICEF (2010) reported that statistics from the Department of Social Welfare (DSW) show a rise in reported child abuse cases, in Malaysia. In 2008, there were 2,780 child abuse reports. Based on the reported figures, neglect is the most common form of child abuse in Malaysia. Out of the 2,780 child abuse cases, 772 offenders were mothers of the victims, while 494 cases were attributed to fathers of the victims. As social 
workers, we argue that these statistics offer sufficient reason to study the child abuse.

\section{Mandatory reporting}

Mandatory child abuse and neglect reporting laws apply to teachers in many countries of the world. The Child Act 2001 of Malaysia (Act 611, Part V, Chapter 2, Section 27-29) requires medical doctors, family members, and child care providers to reporting a child who is physically or emotionally injured as a result of being illtreated, neglected, abandoned or exposed, or who is sexually abused, to the social welfare officers or police (Lembaga Penyelidikan Undang-Undang, 2005).

The number of cases brought to the attention of authorities or child protection services each year by professionals in general, and teachers in particular demonstrate the importance of their role in mandatory reporting. However, such laws have not yet been introduced for teachers in Malaysia, and there is debate about whether the laws should be extended to teachers at all.

In Malaysia as of now, reporting of Child Abuse and Neglect (CAN) is voluntary for teachers. Teacher is important stakeholder for child welfare as they are in close contact with children when they are in the school. Well-functioning child protection systems require teachers holding positive attitudes toward reporting (Choo et al., 2013a). Some practitioners have called for a policy change to include teachers as part of the mandatory reporting (Alavi et al., 2012; Jalzabdi, 2010).

Schools report slightly more than two per cent (61 cases) of the 2780 CAN cases reported nationwide (Department of Social Welfare Malaysia, 2008; Choo et al., 2013).There are many factors that influence either report or not report to authorities both by teachers and other public members regarding possible Child Abuse and Neglect (CAN) in the schools and communities. It is also a fact that there are many unreported cases due to social stigma and lack of access to report makes the child protection in Malaysia or for that matter any other country in the region a much more complex than we think. Global experience shows that only a small proportion of child abuse of children is reported and investigated, and few 
perpetrators are held to account. In addition to mandatory reporting by the family, education, health and welfare staff, crafting a robust child protection monitoring and review capacity building at all levels yield better results in addressing cycle of Child abuse.

The above discussion confirms that Child Abuse is a wicked policy problem that needs further scrutiny. In this paper, we illustrate 'systems change' to advance collaborative strategies will not alone solve the issue of child abuse and protection. On the other hand, a collaborative approach using communitarian social work practice based on enhanced reporting, service delivery monitoring and review capacity mechanisms can provide promising answers. This paper investigates indepth the Malaysian case, and argues that communitarian social work can provide an answer to address the breadth and depth of child abuse in the Malaysian society.

\title{
REPORTING CHILD ABUSE: HELPING OR HURTING?
}

\begin{abstract}
"We need to not just know, but DO something about the abuse in our society. It's going on around us, next to us, behind us, in front of us. We need to know how to recognize victims, identify problems and help the children. With definite numbers, we can see the "who" and the "where". Through that we can find out the "why" and the "how", why is child abuse happening? And how can we stop this from happening?
\end{abstract}

(Ms. Zoe Lim Shu Mei, Age 16, Child Representative Coordinator \& Child Representative for MBPJ Child

Council, speech on 15 December 2010)

In industrialised Asian societies like Hong Kong and Malaysia, there still exist many conditions conducive to child battering. Conditions such as overcrowding, single parenting, long working hours, poverty, rapid social changes, social sanction for harsh discipline, cultural suppression of children's rights in favour of parental rights, and the lack of the full legislation for compulsory reporting and monitoring is a denial of the child's right to full protection. The increases in reporting of abuse cases stimulated by some sensational cases in the press and 
quickly come down in the absence of culture of reporting and policies that fail to promote robust monitoring and review practices.

Many scholars have argued the strengths and weaknesses of mandatory child reporting laws. Citizens have immunity for good faith report of child abuse. A variety of professionals including teachers who work/come in contact with children are required to report, and it is mandatory for them. Failure to do so is a crime. However, the laws and definitions of the expected conduct from citizens, family members, and professionals vary from state to state in the case of USA and may be a country to country (Berliner, 1991; Jenson et al., 2005; Abrahams et al., 1992).

Some practitioners and researchers observe that mandated reporters (professionals) fear that the reporting, itself, may hurt the victim rather than solve the problem as supporting systems do not function or work at cross proposes at times. Also, some professionals are concerned about the client self-determination and issue of confidentiality. In fear of legal procedure to failure to report some may end up over reporting too (Kenny, 2001). 'Over-reporting' is defined by child protection workers who view reports in terms of the existence of sufficient evidence to prosecute (Deisz et al., 1996). Under-reporting was found, however, to exceed overreporting by a large margin for a sample of school teachers (Webster et al., 2005). The notion is that 'mandated reporting' remains a controversial subject despite its strengths. Oz and Balshan (2007) in their work in Israel observed that, there is a large insufficiency of studies looking at the impact of 'reporting' on the victims and their families. Their work presents six cases of suspected sexual abuse to demonstrate some of the inconsistencies in responses to reports within the Israeli system which borrowed many models from the USA.

To sum up, child reporting laws unquestionably provide protection for abused children, punishment and rehabilitation of many abusive adults and the reconstruction of dysfunctional families. The state must assume the role of care and protection of children when parents fail their duty (Berliner, 1991). However, the extent of state intervention in family life and space is also questionable and sometimes may not be warranted. The mandatory reporting that activates the state mechanism can be sometimes intrusive, insensitive, uncomfortable, embarrassing, 
expensive or even humiliating to all parties involved. Although the state's involvement is crucial and vital and is expected to play constructive and supportive role, it may end up with punitive consequences when the review and monitoring mechanisms fail or are not adequate. As a result, the mandatory reporting may not work in the best interest of an abused child and victim assistance in all cases. For example, untrained citizens or neighbours who are not knowledgeable may be reporting cases based on faulty impressions and this over-reporting may tax the ability of social workers to handle the volume of cases that come their way.

\section{EVALUATION OF CHILD SEXUAL ABUSE ALLEGATIONS}

Kuehnle and Connell (2009) edited an extensive volume that described and discussed some of the contested issues and controversies in assessing and evaluating child sexual abuse allegations. Several chapters in this volume challenge, if not condemn, the validity of established forensic methodology likely employed by the evaluator. Much of this edited volume presents a strong emphasis on specificity (compared to the sensitivity). Many of the chapters in Kuehnle and Connell edited volume (2009) critiqued standard and commonly used techniques and approaches to interviewing children who may have been sexually abused, and the criteria for deciding whether they have indeed been sexually abused.

In contrast, Everson et al., (2012) and Faller and Everson (2012) argued that an emphasis on specificity has long dominated the field of forensic assessment of child sexual abuse. There are limitations about the impact of privileging specificity over sensitivity, and its application in actual practice. Reporting, monitoring and review become much more crucial and complex activity due to the very interlinked nature of Child Protection system in a particular country and region. The global goals like the Millennium Development Goals (MDGs) are unachievable unless child protection is an integral part of programmes, strategies and plans for their achievement. 


\section{SERVICE DELIVERY MONITORING AND REVIEW CAPACITY}

Complex policy tribulations are sometimes called 'wicked' problems- not in the sense of evil, but as an issue highly resistant to resolution. If yes, breaking the cycle of child abuse and crafting system of Child protection is often a wicked problem in many countries and Malaysia is not exclusion.

Discussion about ensuring children's rights to protection from abuse, neglect, exploitation and violence is seldom fully addressed. Some initial research evidence shows that current systems and policies for protecting children in Malaysia and other countries in Asia are failing in their primary goal of protecting children from abuse (WHO, 2006a).

The concepts of transparency, accountability, and monitoring and review capacity on service delivery have always been important links in the system of service delivery. World Development Report (WDR) of 2004 argues that failures in service delivery directly linked to failures in accountability relationships. Enhancing capacity and strategic service delivery by all stakeholders involved in the Child Protection system (CPS) is urgent and need of the hour in the ASEAN member countries that included Malaysia. The WDR report of 2004 shows the evidence that direct accountability between users and providers enhances services delivery. It also examined ways of strengthening the mechanism from amplifying voice, increasing transparency and enhancing accountability.

The broad consensus from the social welfare officers in the Penang State consulted while writing this paper stated that the best way to protect children is to prevent child abuse and neglect from happening in the first place. A child protection system impacts multiple outcomes. Despite the research evidence, there are serious gaps in our understanding of the impacts and effectiveness of transparency and accountability initiatives in service delivery. Attempts to address wicked problems are hindered by the substantive, strategic and institutional uncertainties they generate. Hence, they go beyond the capacity of any one organisation to understand and respond to, and disagreements about the best way to tackle them. 


\section{CHILD PROTECTION SERVICE DELIVERY}

An old Malay saying goes; 'biar mati anak jangan mati adat' which means 'to let go a custom is far worse than to let go a child'! This saying reflects the high value that Malaysian culture attaches to customs and customary practices and also shows the way it looks at the children. It also explains why and how custom is given a high rank in the day to day lives of Malaysians. Horoscope indulgence among the Chinese community and astrological beliefs among Indian Malaysian may also result in bias and abuse of children. Recognising the links between customs and abuse, as social workers we need to make informed decisions that are culturally sensitive and appropriate and based on professional value, may not be easy all the time.

Noremy et al., (2012) argued that factors that contributed to the physical child abuse are financial constraints, family crisis, character and disobedience of the children, deviant children, and surroundings of home, conflict with neighbours, and lack of social support, mental illness and influence of alcohol among parents. Out of eight respondents six were women, and the rest of two were men. This study suggests that both biological and step mothers can become physical child abusers due to their poverty, disappearance of husband and other economic stresses.

Five main forms of child abuse known to take place in Malaysia are physical abuse, sexual abuse, emotional abuse, neglect and abandonment. These forms of abuse have been given legal attention and recognition except emotional or psychological abuse. One common emotional abuse is verbal abuse; that is a form of abusive behaviour involving the use of language. Alternatively known as reviling, it is a pattern of behaviour that can seriously interfere with one's positive emotional development and over time, it can lead to a significant detriment to one's selfesteem, emotional well-being and physical state. Although verbal abuse does not leave any outer mark or proof, a verbally abused victim usually suffers by having lower self-worth and low self-esteem. Another categorisation of verbal abuse is trivializing, undermining, threatening, name-calling, forgetting, ordering and denial (Noh \& Talaat, 2012). 
Cook et al., (2001) and Oweis and Diabat (2005) have clearly divided verbal abuse into eleven categories i.e. judging and criticizing, accusing and blaming, abusive anger, discounting, condescending, ignoring, trivializing, blocking and diverting, threatening, abuse disguised as jokes, and sexual harassment. Evans (1993) has noted another interesting and comprehensive understanding of verbal abuse. She noted down fifteen types of verbal abuse. They are withholding, verbal abuse disguised as jokes, trivializing, judging and criticizing, blocking and diverting, name calling, countering, discounting, accusing and blaming, undermining, forgetting, ordering and demanding, denial, abusive anger, and threatening.

The term "abuse" is used without referring to the various types of abuse. Other than child sexual abuse, which receives particular mention under Section 3(1)(b), the Act is silent on the other types of abuse but speaks rather broadly by mentioning the impact of the abuse as to "cause him physical or emotional injury".

Social workers and service officers, who are working with abuses children and families, have to work towards changing those external factors and customary practices that are not in the best interest of the children and their wellbeing. At the same time, one needs to encourage and harvest cultural and customary practices that promote rights and best interests of children.

Service Delivery in Child Protection is mainly individual based. Child protection actions and services can be broadly divided into prevention/awarenessraising activities and services and responsive and reintegration-oriented social services. They are delivered by government agencies, NGOs, religious organisations or a combination of all these in a particular state or country like Malaysia. In this following section, we further analyse how are the child protection service delivery working in Malaysia and is it addressing some of the cultural practices that may unintentionally hinder the child protection service delivery.

The effective delivery of public services in child protection services is crucial for poverty reduction, wellbeing of all children and to achieve development goals. In 
order to improve service delivery mechanisms, it does not suffice to concentrate merely on 'supply side' mechanisms. It involves the need to capacitate the 'demand side' of service delivery by ensuring that the users/stakeholders of child protection services are informed of their rights, duties and entitlements and are enabled to exercise their rights. At the same time, enhanced monitoring and review capacities further augment the quality of Child Protection services by holding the government and other service providers accountable.

\section{MONITORING AND REVIEW CAPACITY}

Monitoring and Review (M\&R) is a significant step in any planning process and to estimate progress. $M \& R$ is crucial to assess impact and effectiveness of $\mathrm{CP}$ programs, exchange best practices and lessons learnt, understand the importance of participatory monitoring and review tools and approaches and to develop the monitoring section of your organizational action plan. Monitoring and Review can be undertaken for a range of purposes, including:

1) to measure impact, outputs, efficiency, effectiveness or change,

2) to strengthen accountability,

3) to facilitate organisational learning,

4) to strengthen partnerships and team building,

5) to support advocacy efforts; and

6) to influence an organisation's culture

One of the objectives of this paper is to contribute to our collective understanding of using participatory and mixed tools that enhance service delivery monitoring and review capacity particularly for child protection service delivery that is politically sensitive, ethical in nature and under reported in most countries. There is a common trap when it comes to monitoring and review programs. Many programs only measure outputs such as the number of posters printed; brochures distributed, advertisements run, workshops held, lectures given, and face-to-face meetings held. These are measures of the program's implementation and not measures of reach, quality, satisfaction or engagement. So how can one avoid this trap is by asking right 
questions and use right tools (Nikku, 2012). In the absence/ wrong use of M\&R tools, it would be impossible to judge/understand: if work plan was going in the right direction, whether progress is been made, and success could be claimed and how future efforts might be improved.

\section{SYSTEMS APPROACH TO CHILD PROTECTION}

A monitoring system consists of a process for regular collection and analysis of a core set of indicators. A system is a collection of components. A systems approach in child protection is new and unfamiliar to many policy-makers and practitioners. The importance of a systems approach is one that fosters identification of the resources and activities needed to produce the desired effects. In a systems view, the resources are called inputs, the activities are processes, and effects are outcomes (UNICEF, 2010a).

The systems approach differs from earlier child protection efforts, which have traditionally focused on single issues such as child trafficking, street children, child labour, emergencies, institutionalization, or HIV and AIDS. Although such efforts have produced substantial benefits, this diffused approach often results in a fragmented child protection response, marked by numerous inefficiencies and pockets of unmet need. All systems are nested within other systems. That is; a given system (e.g., the child protection system) has embedded within its boundaries other systems (e.g., foster care, child protective services reporting, case management).

\section{Quality Monitoring Approach}

A good monitoring system includes both process monitoring \& impact monitoring elements. Process monitoring is to review and plan work on a regular basis, assessing whether activities are carried out as planned and identifying and dealing with problems as they arise. Whereas, impact monitoring is all about measuring progress towards meeting ( for example Child Protection) program objectives as identifying need to change objectives ( may not change as the main objective is to protect children ) and changing work in response to shifting circumstances without altering the overall direction. 
It is often easy to overlook impact monitoring at the expense of process monitoring. To bring in the quality to $M \& R$, we need to determine the systems/ programs of care and protection to be monitored and defining performance standards and indicators, choosing appropriate data collection methods and designing and testing monitoring tools. For example, exit interviews with children leaving care homes, interviews with service providers, and reviews of medical and social worker records), analysing and applying quality data and assuming ownership of the monitoring process is the key.

\section{Incremental approach to monitoring and review}

One need to start with a simple system focused on one or a few Child Protection services and expands it as experience and resources permit. Then, expand the monitoring system in terms of expansion in space, time, scope, methods, and finally, sustain the system by providing adequate resources and making monitoring a routine part of the workload. Crafting an effective monitoring and review system is based on few but regular practices within an organisation. Data collected should be used to identify the presence and causes of performance problems. Data are collected regularly to monitor the trend of indicators over time and are used to guide management decisions. And finally data collection is a routine activity integrated into daily tasks.

\section{Monitoring and Review Tools}

How to choose the right monitoring tools is a difficult to decide as there are so many tools available now. Some of the examples are the Participatory Monitoring (PM), Participatory Impact Monitoring (PIM), Process Monitoring (ProM), Participatory Community Monitoring (PCM), Citizen Monitoring (CM), and Participatory Monitoring and Evaluation (PM\&E) developed on the basis of Participatory Action Research (PAR) based on works of Freire (1972) and Fals Borda (1985).

There are some differences between traditional monitoring and participatory monitoring tools. In the case of traditional monitoring, the purpose of monitoring is to measure progress to relative to the project plan. In the case of participatory monitoring, it is to measure success both qualitatively and quantitatively and also to 
develop lessons learned to integrate into the project and makes a subjective judgment, whereas in traditional monitoring it has to be the objective analysis mostly using quantitative methods.

For the child protection staff and supervisors, there are more methods and tools that are available to carry out their job. Some of the useful M\&R tools are performance indicators, the logical framework approach, formal surveys, public expenditure tracking surveys, cost-benefit and cost-effectiveness analysis, impact monitoring and evaluation, rapid appraisal methods, participatory methods, card sorting and ranking, vignettes, story with a gap and pocket chart. One has to be careful, however, in choosing these tools as some of these tools and methods are complementary, and some are substitutes. Some tools have broad applicability, while others are quite narrow in their uses. The choice of which tools are appropriate for any given context will depend on a range of considerations such as the type of M\&R, time, resources available, stakeholders involved, scale and scope.

\section{Review Capacity}

Capacity refers to the facilities, material resources, skilled personnel, and funding needed to operate the system. These capacities have to be allocated in relation to the design of the system. One important capacity is decision making. At the organizational level, decision making is used to allocate capacity to meet the purpose of the system. Procurement of capacity is another important aspect of what the organization has to do. Structures and capacity for monitoring, management, and decision making are especially critical, particularly in view of the need to interact with and adapt to any externalities present in the environment (UNICEF, 2010). Review Capacity is the assessment at one point in time of the progress of a piece of work or a particular aspect of a piece of work. And can be extensive or in-depth, formal or informal and can be carried out internally or externally.

\section{Decision Making}

Decisions involve many intangibles that need to be traded off. Child protection services staff needs to make decisions every day. And we knew these decisions effect 
the live if children in care. Many decisions, especially those for child protection and care services, should be made through a systematic process (Nikku, 2012).

Among other decision-making methods, we found the Analytic Hierarchy Process (AHP) is very useful. The AHP was developed by Professor Thomas L. Saaty in the 1970s. It is a structured method for solving complex decision problems. The AHP is a theory of measurement through pairwise comparisons and relies on the judgments of experts to derive priority scales (Saaty, 2008). It has three major functions. Firstly, it helps to decompose a decision problem into measurable criteria. Secondly, it helps to assign a weight to each criterion; which is usually referred to as prioritizing (or ranking) the criteria. Thirdly, each possible solution can be scored based on the weighted criteria.

It is useful in making critical decisions, such as the evaluation of alternative strategies. Assigning weights to criteria provide a more accurate judgment. In addition, the AHP differentiates it from other decision-making methods as it employs a consistency test that can purify the responses to the questionnaire, and an iterative process that can improve the consistency of measuring.

Most Significant Change Technique (MSC): This tool can be used to the regular collection and participatory interpretation of stories about change and is not a standalone approach to monitoring and assessment. All stakeholders in the program involved in deciding the sorts of changes to be recorded, same questions are asked of everyone resulting stories are rigorously and regularly collected. Stories are then analysed, discussed and filtered (voting), verified, and documented.

Systemic Monitoring and Review Technique (SMART): Using this tool departments/ agencies analyse risks and measure outcomes against key performance indicators. This automated tool also helps managers monitor and analyse the root causes of Child (protection) issues and create a culture of compliance aimed at improving financial stability, compliance, and quality.

Mixed method approach: As child protection services are moving from a traditional case by case to a systems approach, enhancing service delivery monitoring and review capacities of the $\mathrm{CP}$ staff members play a key role. A mixed 
method approach by carrying out outcome mapping, or action-reflection approaches can help explain why change happened and how donor/government inputs influenced development or supported key actors in a particular program/ situation. Mixture of methods can provide the donor/ government with a complete picture of the changes that have happened, and the reasons for those changes, across short, medium, and longer term time frames.

Using mixed method approach to $M \& R$ raise the standard of the assessment and provide for triangulation of assessments; one method compensates the weakness in others and provides a cross-check on the findings of the study of the same phenomenon (Bamberger \& Segone, 2011). It also allows for complementarity; different methods can explore different elements of the program and the results of one method can inform the development of the next. Most importantly, it helps to uncover paradoxes, contradictions and new perspectives, broaden and widen the range of the study to include more issues, e.g. contextual understanding, and participants lived experience, as well as changes in observable phenomena. Most significantly, a mixed methods approach to monitoring and review provides greater rigour and insights.

\section{CONCLUSION AND WAY FORWARD}

In this paper, we have argued that child abuse is a wicked problem in Malaysia and elsewhere. What is needed is not lip service, promises or mere political statements but commitment and action. Implementing communitarian social work models provide ways to break the vicious cycle of all forms of child abuse in Malaysian society. All stakeholders need to be aware and agree that that raising children is by nature labour intensive, non-negotiable, morally and legally binding.

Social Workers need to update about reporting procedures and legal requirements. The reporting procedures should be simple and specific guidelines on how and where to report should be made available in different languages used in Malaysia given the multicultural, religion nature of the society. An area of social work research that is critical to the field of child sexual abuse is an understanding of childhood, sexuality in children of today as they increasingly vulnerable to different 
types of perpetrators inside and outside homes and schools. As different groups of professionals are mandated to report child sexual abuse, the knowledge of sexuality within the family and what is normal and abnormal practice becomes significant.

A raise in the number of child abuse cases reported in Malaysia now than was the case 20 years ago, is certainly a policy achievement in the direction of crafting a robust child protection system. However, further studies and policy efforts are necessary to capture the incidence and prevalence rates of child abuse. Further discussion and policy measures need to be in place to reach out to the conflict between the welfare and rights of children and parents and primary caregivers. Agreeing with Powell (1987), social workers and other professionals working with and for children, need to understand current family practices regarding rights and sexual knowledge children do acquire in no abusive situations. The data and research insights generated from such research should be used to frame planned child protection social policies that protect the rights of children while still affirming the rights of the accused. As a way forward, we envision Malaysian social work that plays a critical part in bringing the various actors and their agendas and child abuse as a whole out of the hidden cultural and social practices and break the cycle of abuse.

\section{REFERENCES}

Abrahams N., Casey, K., \& Daro, D. (1992). Teachers' knowledge, attitudes, and beliefs about child abuse and its prevention. Child Abuse \& Neglect, 16, 229238

ACHR (2013). India's Hell Holes: Child Sexual Assault in Juvenile Justice Homes. New Delhi: Asian Centre For Human Rights. Retrieved from http://www.achrweb.org/reports /india/IndiasHellHoles 2013.pdf

Alavi, K., Amin, A. S., Subhi, N., Mohamad, M. S., \& Sarnon, N. (2012). Kerja sosial di sekolah: Memahami dan menangani penderaan kanak-kanak [Social Work at School: Understanding and Dealing with Child Abuse] Jurnal e-bangi, 7(1), 17-37.

Bamberger, M., \& Segone M. (2011). How to design and manage equity-focused evaluation, New York: UNICEF

Berliner, L. (1991). Reporting child abuse helping or hurting?. Journal of Interpersonal Violence, 6(1), 110-111. 
Catani, C., Schauer, E., \& Neuner F. (2008). Beyond individual war trauma: domestic violence against children in Afghanistan and Sri Lanka. Journal of Marital and Family Therapy, 34 (2), 165-76.

Choo, W.Y., Walsh, K., Chinna, K., \& Nai, P. T (2013a). Teacher reporting attitudes scale (TRAS) confirmatory and exploratory factor analyses with a Malaysian sample. Journal of Interpersonal Violence, 28 (2), 231-253.

Choo, W.Y., Walsh, K., Marret, M. J., China, K., \& Nai, P. T. (2013). Are Malaysian teachers ready to assume the duties of reporting child abuse and neglect?, Child Abuse Review, 22, 93-107.

Cook, K. J., Green, M., \& Topp, R. V. (2001). Exploring the Impact on Physician Verbal Abuse on Nurses. Aorn Journal, 74, 237-241.

Deisz, R., Doueck, H. J., George, N., \& Levine, M. (1996). Reasonable cause: A qualitative study of mandated reporting, Child Abuse and Neglect, 20(4), 275287.

Evans, P. (1993). Verbal Abuse Survivors Speak Out: On Relationship and Recovery. Holdbrook, MA: Adams Media Corporation.

Everson, M. D., Sandoval, J. M., Berson, N., Crowson, M., \& Robinson, H. (2012) Reliability of professional judgments in forensic child sexual abuse evaluations: Unsettled or unsettling science?. Journal of Child Sexual Abuse, 21(1), 72-90.

Faller, K. C., \& Everson, M. D. (2012). Contested issues in the evaluation of child sexual abuse allegations: Why consensus on best practice remains elusive. Journal of Child Sexual Abuse, 21(1), 3-18

Government of Malaysia. (2005). Response to the United Nations Secretary General's study on violence against children: Questionnaire to Governments. Kuala Lumpur: Government of Malaysia.

Jal Zabdi, M. Y. (2010). The crime of child abuse and neglect [Jenayah Penderaan Kanak- Kanak]. Kuala Lumpur: University of Malaya Press.

Jensen, T. K., Gulbrandsen, W., Mossige, S., Reichelt, S., \& Tjersland, O. D. (2005). Reporting possible sexual abuse: A qualitative study on children's perspectives and the context for disclosure. Child Abuse \& Neglect, 29, 1395-1413.

Karlsson, L., \& Karkara, R. (2003) Working with boys and men to end gender discrimination and sexual abuse of boys and girls. Save the Children SwedenDenmark : Kathamndu

Kenny, M. C. (2001). Child abuse reporting: Teachers' perceived deterrents. Child Abuse \& Neglect, 25, 81-92.

Kluft, R. P. (Ed.). (1985). Childhood antecedents of multiple personality. American Psychiatric Publication. 
Kuehnle, K., \& Connell, M. (2009). The evaluation of child sexual abuse allegations: A comprehensive guide to assessment. Hoboken, NJ: Wiley.

Muda, Tengku Fatimah Muliana binti Tengku \& Alwi, Engku Ahmad Zaki bin Engku ( 2012) Care and Protection against Child Abuse: With Special Reference to Malaysia Child Act 2001, Asian Social Science, 8 (1), 202-208.

Munir, A. B. B.(1993). Child protection: Principles and applications. Child Abuse Review, 2, 119-126.

Nikku, B. R.(2012). Enhancing service delivery monitoring and review capacity., Paper presented at the Child Protection Conference 2012: Enhancing capacity and strategic service delivery within a national and regional context, November 20-22, 2012, organised by the Ministry of Women, Family and Community Development, Malaysia and UNICEF.

Noh, C. H. C., \& Talaat, W. I. A. W. (2012). Verbal abuse on children: Does it amount to child abuse under the Malaysian law?. Asian Social Science, 8(6), 224-228.

Noremy, M. A., Zulkarnain, A. H., Kelvin, F., Adanan, M. J., \& Sarah, W. M. H. (2012). Physical child abuse: What are the external factors? Asian Social Science, 8(9), 83-91.

Oweis, A., \& Diabat, K. M. (2005). Jordanian nurses perception of physicians' verbal abuse: Findings from a questionnaire survey. International Journal of Nursing Studies, 42, 881-888.

Oz, S., \& Balshan, D. (2007). Mandatory reporting of childhood sexual abuse in Israel: What happens after the report? Journal of Child Sexual Abuse, 16(4),122.

Powell, G. J. (1987). The multifaceted aspects of child sexual abuse summary and conclusions. Journal of Interpersonal Violence, 2(4), 435-445.

Saaty, T. L (2008). Decision making with the analytic hierarchy process, International Journal Services Sciences, 1(1), 83-98. Retrieved from http://www.colorado.edu/geography/leyk/geog_5113/readings/saaty_2008.pdf.

Terling-Watt, T. (2000). A communitarian critique of the child protective system. Journal of Sociology and Social Welfare, 27(4), 3-23.

U.S. Department of Health \& Human Services ( 2011). Child maltreatment 2011. Retrieved from http://www.acf.hhs.gov/sites/default/files/cb/cm11.pdf.

UNICEF (2010). Child abuse in Malaysia- Fact sheet. Retrieved from http://uaastatic.s3.amazonaws.com/GetonBoard-Factsheet-Child-Abuse-in-Malaysia.pdf.

UNICEF (2010a). Adapting a systems approach to child protection: Key concepts and considerations. New York: UNICEF.

UNICEF (2012). Child Maltreatment: Prevalence, Incidence and Consequences in East Asia and the Pacific- A Systematic Review of Research, Bangkok: UNICEF East Asia and Pacific Regional Office (EAPRO) 
Webster, S. W., O'Toole, R., O’Toole, A. W., \& Lucal, B. (2005). Overreporting and underreporting of child abuse: Teachers' use of professional discretion. Child Abuse \& Neglect, 29(11), 1281-1296.

Women's International Network News (1990). Malaysia: Sexual abuse increasingmostly by fathers/male relatives. Summer 90, 16 (3). Retrieved from http://tinyurl.com/m952myn

World Health Organization (2006). Preventing child maltreatment - A guide to taking action and generating evidence. Geneva: WHO.

World Health Organization (2006a). National report on violence and health Malaysia. Kobe: WHO Kobe Centre

World Health Organization [WHO] (2002). World report on violence and health, Summary Report. Retrieved from http://www.who.int/violence_ injury_prevention/ violence /world_report/en/summary_en.pdf.

Yusoff Mohd, Jal Zabadi., Siti Hajar Abu Bakar Ah and Weatherley, Richard (2008) International Trends in Child Abuse Prevention and Risk Assessment: Implications for Malaysia, Malaysian Journal of Social Administration, 5, 2150 . 